\title{
Impact of sagittal spinopelvic alignment on clinical outcomes after decompression surgery for lumbar spinal canal stenosis without coronal imbalance
}

\author{
Tomohiro Hikata, MD, PhD, Kota Watanabe, MD, PhD, Nobuyuki Fujita, MD, PhD, \\ Akio Iwanami, MD, PhD, Naobumi Hosogane, MD, PhD, Ken Ishii, MD, PhD, \\ Masaya Nakamura, MD, PhD, Yoshiaki Toyama, MD, PhD, and Morio Matsumoto, MD, PhD \\ Department of Orthopaedic Surgery, Keio University School of Medicine, Tokyo, Japan
}

\begin{abstract}
OBJECT The object of this study was to investigate correlations between sagittal spinopelvic alignment and improvements in clinical and quality-of-life (QOL) outcomes after lumbar decompression surgery for lumbar spinal canal stenosis (LCS) without coronal imbalance.

METHODS The authors retrospectively reviewed data from consecutive patients treated for LCS with decompression surgery in the period from 2009 through 2011. They examined correlations between preoperative or postoperative sagittal vertical axis (SVA) and radiological parameters, clinical outcomes, and health-related (HR)QOL scores in patients divided according to SVA. Clinical outcomes were assessed according to Japanese Orthopaedic Association (JOA) and visual analog scale (VAS) scores. Health-related QOL was evaluated using the Roland-Morris Disability Questionnaire (RMDQ) and the JOA Back Pain Evaluation Questionnaire (JOABPEQ).
\end{abstract}

RESULTS One hundred nine patients were eligible for inclusion in the study. Compared to patients with normal sagittal alignment prior to surgery (Group A: SVA $<50 \mathrm{~mm}$ ), those with preoperative sagittal imbalance (Group B: SVA $\geq 50$ $\mathrm{mm}$ ) had significantly smaller lumbar lordosis and thoracic kyphosis angles and larger pelvic tilt. In Group B, there was a significant decrease in postoperative SVA compared with the preoperative SVA $(76.3 \pm 29.7 \mathrm{~mm}$ vs $54.3 \pm 39.8 \mathrm{~mm}, p=$ 0.004). The patients in Group B with severe preoperative sagittal imbalance (SVA $>80 \mathrm{~mm}$ ) had residual sagittal imbalance after surgery $(82.8 \pm 41.6 \mathrm{~mm})$. There were no significant differences in clinical and HRQOL outcomes between Groups A and B. Compared to patients with normal postoperative SVA (Group C: SVA $<50 \mathrm{~mm}$ ), patients with a postoperative SVA $\geq 50 \mathrm{~mm}$ (Group D) had significantly lower JOABPEQ scores, both preoperative and postoperative, for walking ability (preop: $36.6 \pm 26.3$ vs $22.7 \pm 26.0, p=0.038$, respectively; postop: $71.1 \pm 30.4$ vs $42.5 \pm 29.6, p<0.001$ ) and social functioning (preop: $38.7 \pm 18.5$ vs $30.2 \pm 16.7, p=0.045$; postop: $67.0 \pm 25.8$ vs $49.6 \pm 20.0, p=0.001$ ), as well as significantly higher postoperative RMDQ $(4.9 \pm 5.2$ vs $7.9 \pm 5.7, p=0.015)$ and VAS scores for low-back pain $(2.68 \pm$ 2.69 vs $3.94 \pm 2.59, p=0.039$ ).

CONCLUSIONS Preoperative sagittal balance was not significantly correlated with clinical or HRQOL outcomes after decompression surgery in LCS patients without coronal imbalance. Decompression surgery improved the SVA value in patients with preoperative sagittal imbalance; however, the patients with severe preoperative sagittal imbalance (SVA > $80 \mathrm{~mm}$ ) had residual imbalance after decompression surgery. Both clinical and HRQOL outcomes were negatively affected by postoperative residual sagittal imbalance.

http://thejns.org/doi/abs/10.3171/2015.1.SPINE14642

KEY WORDS lumbar spinal canal stenosis; spinopelvic alignment; decompression surgery; sagittal vertical axis

ABBREVIATIONS C7-CSVL = C-7 plumb line deviation from the central sacral vertical line; $E B L=$ estimated blood loss; $\mathrm{HRQOL}=$ health-related quality of life; JOA = Japanese Orthopaedic Association; JOABPEQ = JOA Back Pain Evaluation Questionnaire; LBP = low-back pain; LCS = lumbar spinal canal stenosis; $M C I D=$ minimum clinically important difference; RMDQ = Roland-Morris Disability Questionnaire; $S V A=$ sagittal vertical axis; VAS = visual analog scale.

SUBMITTED June 30, 2014. ACCEPTED January 13, 2015.

INCLUDE WHEN CITING Published online July 3, 2015; DOI: 10.3171/2015.1.SPINE14642.

DISCLOSURE The authors report no conflict of interest concerning the materials or methods in this study or the findings specified in this paper. 
$\mathrm{A}$ $\mathrm{s}$ the aging population has grown in recent years, the prevalence of lumbar spinal canal stenosis (LCS) and other degenerative spinal diseases has also increased. Lumbar canal stenosis causes low-back pain (LBP), leg pain, neurogenic intermittent claudication, and bladder and rectal disorders, all of which affect health-related quality of life (HRQOL). Lumbar decompression surgery, one of the most common surgical treatments for LCS, usually improves neurogenic claudication, leg pain, and, eventually, HRQOL.

Sagittal spinal alignment is an important factor in managing lumbar degenerative diseases and LBP. ${ }^{2,11,12,25}$ Several studies have shown the importance of sagittal spinopelvic alignment for maintaining balanced posture, both in the normal population and in patients with global sagittal imbalance. However, the impact of preoperative sagittal spinopelvic malalignment on clinical outcomes after lumbar decompression surgery for LCS without coronal imbalance has not been clarified. Moreover, quantitative changes in sagittal spinal alignment after decompression surgery for LCS and how those changes relate to clinical outcome have not been reported. This study was conducted to analyze posture before and after decompression surgery for degenerative LCS, to evaluate the influence of spinal alignment on the improvement of clinical symptoms, and to clarify the impact of residual sagittal malalignment on clinical outcomes after decompression surgery.

\section{Methods \\ Study Design}

We retrospectively reviewed medical records from patients who had undergone elective lumbar spinous process-splitting laminectomy to treat LCS in the period from 2009 through 2011. This procedure was performed as described elsewhere. ${ }^{27}$ For each patient, the levels to be decompressed were determined based on neurological examination and preoperative MRI and myelography. Six spine surgeons with more than 15 years' experience in spine surgery performed the procedure in the patients in this study. All operative procedures were standardized among the surgeons. Postoperative care was standardized for all patients, who were allowed to sit up and walk without lumbar support on the 1st postoperative day. After the drain tube was removed on the 2 nd postoperative day, walking exercises and muscle training on the lower extremities were started.

Patients were eligible for inclusion in the study if they 1) had complained of leg pain, leg numbness, and neurological claudication before the operation; 2) had been followed up for at least 1 year; 3 ) had 3 or fewer decompression levels; 4) had slippage $\leq 25 \%$ on a flexion lateral radiograph; and 5) had not sustained a vertebral fracture during the follow-up period. We excluded patients with 1) only LBP from sagittal imbalance, 2 ) preoperative degenerative lumbar scoliosis $>15^{\circ}$, and 3 ) coronal imbalance of more than $40 \mathrm{~mm}$ of the $\mathrm{C}-7$ plumb line deviation from the central sacral vertical line (C7-CSVL) in a whole-spine coronal standing view.

We assessed the following clinical parameters and operative data: patient age, sex, follow-up period, disease duration, segments decompressed, estimated blood loss (EBL), and time in surgery. Neurological status was evaluated prior to surgery and at the final follow-up by using the Japanese Orthopaedic Association (JOA) scoring system (29 possible points). Recovery rate was calculated as (postoperative JOA score - preoperative JOA score)/(29 preoperative JOA score) $\times 100(\%) .{ }^{5}$ The severity of LBP, leg pain, and leg numbness was evaluated using the visual analog scale (VAS). We also assessed HRQOL outcomes with the Roland-Morris Disability Questionnaire (RMDQ) and the JOA Back Pain Evaluation Questionnaire (JOABPEQ). ${ }^{8}$

\section{Radiological Parameters}

All patients underwent full-length standing wholespine radiography (posteroanterior and lateral) before surgery and at the final follow-up. As reported previously, ${ }^{24}$ we used standard measurements to assess thoracolumbar and lumbar Cobb angles, coronal balance (C7-CSVL), sagittal balance (sagittal vertical axis [SVA]), lumbar lordosis (T12-S1), thoracic kyphosis (T5-12), thoracolumbar kyphosis (T10-L2), pelvic incidence, pelvic tilt, and sacral slope. The first author (T.H), who was not the primary surgeon, conducted the radiological measurements.

Rose et al. defined the ideal sagittal balance as an SVA $<50 \mathrm{~mm} .{ }^{23}$ Schwab et al. demonstrated an SVA threshold of $47 \mathrm{~mm}$ or more for disability. ${ }^{24}$ Therefore, we grouped patients according to preoperative SVA values $<50 \mathrm{~mm}$ (Group A) or $\geq 50 \mathrm{~mm}$ (Group B) and postoperative SVA values $<50 \mathrm{~mm}$ (Group C) or $\geq 50 \mathrm{~mm}$ (Group D). Radiological parameters, clinical outcomes, and HRQOL outcomes were compared statistically among these groups.

\section{Statistical Analysis}

Statistical analyses were conducted using chi-square and Student t-tests. A p value $<0.05$ indicated statistical significance. Values are expressed as the mean \pm standard deviation.

\section{Results}

\section{Demographic Data}

One hundred nine patients, 65 men and 44 women, met the study inclusion criteria. The mean age at the time of surgery was 70.7 years (range $42-89$ years), and the mean follow-up was 2.6 years (range 1.0-4.2 years). We first analyzed patients according to preoperative SVA, with 65 patients in Group A (SVA $<50 \mathrm{~mm})$ and 44 in Group B (SVA $\geq 50 \mathrm{~mm}$ ). The demographic data for these groups are summarized in Table 1. Groups A and B did not differ significantly in age, sex, duration of follow-up, disease duration, number of decompression segments, EBL, or time in surgery.

\section{Preoperative Radiological Parameters}

Preoperative radiological parameters for Groups A and $B$ are summarized in Table 2. The mean SVA value was $22.8 \pm 19.9 \mathrm{~mm}$ in Group A and $76.3 \pm 29.7 \mathrm{~mm}$ in Group B ( $\mathrm{p}<0.001)$. Lumbar lordosis, pelvic tilt, and thoracic kyphosis differed significantly between Groups A and 
TABLE 1. Demographic and clinical characteristics of 109 patients treated for LCS, grouped according to preoperative SVA values*

\begin{tabular}{lccc}
\hline \multicolumn{1}{c}{ Parameter } & Group A & Group B & p Value† \\
\hline No. of cases & 65 & 44 & \\
\hline Mean age in yrs & $70.7 \pm 8.5$ & $70.6 \pm 9.6$ & 0.938 \\
\hline Sex (M/F) & $38 / 27$ & $27 / 17$ & 0.762 \\
\hline Mean FU period in yrs & $2.6 \pm 0.8$ & $2.5 \pm 0.9$ & 0.715 \\
\hline $\begin{array}{l}\text { Mean disease duration in yrs } \\
\text { Decompression segments } \\
\text { (no. of cases) }\end{array}$ & $4.1 \pm 3.5$ & $3.3 \pm 3.3$ & 0.277 \\
\hline 1 & & & \\
\hline 2 & 25 & 22 & 0.343 \\
\hline 3 & 12 & 13 & \\
\hline $\begin{array}{c}\text { Mean no. of decompression } \\
\text { segments }\end{array}$ & $1.82 \pm 0.77$ & $1.70 \pm 0.79$ & 0.471 \\
\hline $\begin{array}{c}\text { Decompression level (no. of } \\
\text { cases) }\end{array}$ & & & \\
\hline L1-2 & 2 & & \\
\hline L2-3 & 12 & 14 & \\
\hline L3-4 & 44 & 20 & \\
\hline L4-5 & 58 & 38 & \\
\hline L5-S1 & 2 & 2 & \\
\hline Mean EBL in g & $20.1 \pm 48.2$ & $36.6 \pm 84.0$ & 0.244 \\
\hline Mean operation time in min & $68.2 \pm 30.6$ & $63.4 \pm 29.0$ & 0.407 \\
\hline
\end{tabular}

$\mathrm{FU}=$ follow-up.

* Values are expressed as the mean \pm standard deviation unless indicated otherwise.

$\dagger$ Chi-square test and Student t-test were used as appropriate.

$\mathrm{B}$, respectively: $-39.8^{\circ} \pm 13.0^{\circ}$ versus $-26.8^{\circ} \pm 15.5^{\circ}, \mathrm{p}<$ $0.001 ; 19.7^{\circ} \pm 8.1^{\circ}$ versus $24.2^{\circ} \pm 9.8^{\circ}, \mathrm{p}=0.015$; and $22.1^{\circ}$ $\pm 10.3^{\circ}$ versus $17.9^{\circ} \pm 10.8^{\circ}, \mathrm{p}=0.045$. There were no significant differences in other preoperative radiographic parameters between the 2 groups. These findings indicated that patients in Group B (preoperative SVA $\geq 50 \mathrm{~mm}$ ) had sagittal imbalance with a loss of lumbar lordosis and thoracic kyphosis and with pelvic retroversion.

\section{Correlations Between Preoperative Sagittal Balance and Clinical Outcome}

Table 3 shows the JOABPEQ scores for Groups A and $B$ in the categories of LBP, lumbar function, walking ability, social-life function, and mental health. On average, both groups improved in every category. There were no statistically significant differences in the JOABPEQ scores between the 2 groups; however, the postoperative LBP score trended toward a low score in Group B, compared with that in Group A $(61.5 \pm 36.3$ vs $75.4 \pm 33.0$, respectively, $\mathrm{p}=0.089$ ).

There were no significant differences between the 2 groups in preoperative or postoperative VAS scores (LBP, leg pain, and leg numbness), RMDQ scores, or JOA scores. Patients in Groups A and B showed similar improvements in these scores (Tables 4 and 5). Overall, these results indicated that preoperative sagittal balance did not have any
TABLE 2. Preoperative radiological parameters in 109 patients treated for LCS, grouped according to preoperative SVA values

\begin{tabular}{lccc}
\hline \multicolumn{1}{c}{ Parameter } & Group A & Group B & p Value \\
\hline Mean SVA $(\mathrm{mm})$ & $22.8 \pm 19.9$ & $76.3 \pm 29.7$ & $<0.001^{*}$ \\
\hline Mean LL: T12-S1 $\left(^{\circ}\right)$ & $-39.8 \pm 13.0$ & $-26.8 \pm 15.5$ & $<0.001^{*}$ \\
\hline Mean Cobb $\left(^{\circ}\right)$ & $6.4 \pm 5.9$ & $6.7 \pm 5.4$ & 0.803 \\
\hline Mean PT $\left(^{\circ}\right)$ & $19.7 \pm 8.1$ & $24.2 \pm 9.8$ & $0.015^{*}$ \\
\hline Mean SS $\left(^{\circ}\right)$ & $27.4 \pm 8.7$ & $24.2 \pm 9.5$ & 0.081 \\
\hline Mean PI $\left({ }^{\circ}\right)$ & $47.1 \pm 9.6$ & $48.4 \pm 10.0$ & 0.513 \\
\hline Mean TK: T5-12 $\left(^{\circ}\right)$ & $22.1 \pm 10.3$ & $17.9 \pm 10.8$ & $0.045^{*}$ \\
\hline Mean TLK: T10-L2 $\left(^{\circ}\right)$ & $5.7 \pm 7.5$ & $7.9 \pm 10.0$ & 0.203 \\
\hline Cor bal $(\mathrm{mm})$ & $11.6 \pm 10.8$ & $15.2 \pm 12.0$ & 0.109 \\
\hline
\end{tabular}

$\mathrm{Cobb}=$ thoracolumbar and lumbar Cobb angle; Cor bal $=$ coronal balance $(\mathrm{C} 7-$ CSVL); LL = lumbar lordosis; $\mathrm{PI}=$ pelvic incidence; $\mathrm{PT}$ = pelvic tilt; $\mathrm{SS}$ = sacral slope; $\mathrm{TK}=$ thoracic kyphosis; TLK = thoracolumbar kyphosis.

* Statistically significant.

significant impact on clinical or HRQOL outcomes after lumbar decompression surgery for LCS without coronal imbalance.

\section{Changes in Radiological Parameters After Decompression Surgery}

Changes in radiological parameters for Groups A and B are summarized in Table 6. In Group B, the mean postoperative SVA decreased significantly from the preoperative value $(54.3 \pm 39.8 \mathrm{~mm}$ vs $76.3 \pm 29.7 \mathrm{~mm}$, respectively, $\mathrm{p}=$ 0.004; Fig. 1). In Group A, the SVA value did not change after surgery (preoperative $22.8 \pm 19.9 \mathrm{~mm}$ vs postoperative $24.8 \pm 38.2 \mathrm{~mm}, \mathrm{p}=0.703$ ). Moreover, lumbar lordosis and sacral slope increased significantly after surgery in Group B $\left(-26.8^{\circ} \pm 15.5^{\circ}\right.$ vs $-33.6^{\circ} \pm 14.2^{\circ}, \mathrm{p}=0.035$; and $24.2^{\circ} \pm 9.5^{\circ}$ vs $28.3^{\circ} \pm 8.8^{\circ}, \mathrm{p}=0.041$, respectively), while there was no change in the spinopelvic parameters after surgery in Group A.

TABLE 3. Mean JOABPEQ scores in 109 patients treated for LCS, grouped according to preoperative SVA values

\begin{tabular}{lccc}
\hline Parameter & Group A & Group B & p Value \\
\hline LBP & & & \\
$\quad$ Preop & $37.5 \pm 30.5$ & $44.3 \pm 31.0$ & 0.578 \\
$\quad$ Postop & $75.4 \pm 33.0$ & $61.5 \pm 36.3$ & 0.089 \\
\hline Lumbar function & & & \\
$\quad$ Preop & $51.7 \pm 25.6$ & $56.7 \pm 26.7$ & 0.424 \\
$\quad$ Postop & $74.8 \pm 27.4$ & $68.0 \pm 29.4$ & 0.316 \\
\hline Walking ability & & & \\
$\quad$ Preop & $34.5 \pm 27.2$ & $30.9 \pm 26.3$ & 0.543 \\
$\quad$ Postop & $65.5 \pm 33.2$ & $60.6 \pm 32.0$ & 0.491 \\
\hline Social-life function & & & \\
$\quad$ Preop & $36.8 \pm 18.5$ & $35.8 \pm 18.4$ & 0.811 \\
$\quad$ Postop & $64.0 \pm 25.7$ & $59.8 \pm 25.1$ & 0.436 \\
\hline Mental health & & & \\
$\quad$ Preop & $42.3 \pm 17.8$ & $44.1 \pm 19.1$ & 0.667 \\
$\quad$ Postop & $59.4 \pm 17.6$ & $54.7 \pm 18.4$ & 0.235 \\
\hline
\end{tabular}


TABLE 4. Mean VAS scores in 109 patients treated for LCS, grouped according to preoperative SVA values*

\begin{tabular}{cccc}
\hline Parameter & Group A & Group B & p Value \\
\hline LBP & & & \\
Preop & $5.55 \pm 2.80$ & $5.65 \pm 2.75$ & 0.872 \\
Postop & $3.05 \pm 2.69$ & $3.03 \pm 2.79$ & 0.967 \\
Change & $2.50 \pm 3.45$ & $2.62 \pm 2.97$ & 0.859 \\
\hline Leg pain & & & \\
Preop & $7.18 \pm 2.15$ & $6.36 \pm 2.50$ & 0.137 \\
Postop & $3.09 \pm 3.06$ & $3.45 \pm 3.53$ & 0.878 \\
Change & $4.09 \pm 3.29$ & $2.91 \pm 3.94$ & 0.221 \\
Leg numbness & & & \\
Preop & $6.84 \pm 2.26$ & $6.42 \pm 2.88$ & 0.457 \\
Postop & $3.66 \pm 3.23$ & $4.15 \pm 3.37$ & 0.489 \\
Change & $3.18 \pm 3.53$ & $2.27 \pm 4.01$ & 0.267 \\
\hline
\end{tabular}

* Change was calculated as (postoperative value - preoperative value).

We further analyzed the change in the SVA value in Group B. The mean preoperative SVA value in Group B was $76.3 \mathrm{~mm}$, and we divided the Group B patients into 2 subcategories using an SVA of $80 \mathrm{~mm}$ as the cutoff value: 50-80 mm for Group B1 and $>80 \mathrm{~mm}$ for Group B2 (Table 7). The SVA values for these groups significantly improved after surgery: The change in SVA value for Group B1 was $-18.1 \pm 35.9 \mathrm{~mm}(\mathrm{p}=0.005)$; for Group B2, -31.2 $\pm 36.6 \mathrm{~mm}(\mathrm{p}=0.036)$. The mean SVA value in Group B1 improved to less than $50 \mathrm{~mm}$ after surgery $(42.4 \pm 32.8$ $\mathrm{mm})$. On the other hand, the postoperative SVA value in Group B2 was $82.8 \pm 41.6 \mathrm{~mm}$. The patients with severe preoperative sagittal imbalance (SVA $>80 \mathrm{~mm}$ ) had residual sagittal imbalance after decompression surgery.

\section{Correlations Between Postoperative SVA and Clinical Outcomes}

We next grouped patients by postoperative SVA values $<50 \mathrm{~mm}$ (Group C) or $\geq 50 \mathrm{~mm}$ (Group D). There were 76 patients in Group C (53 from Group A and 23 from Group B) and 33 patients in Group D (12 from Group A and 21 from Group B). The distribution of patients according to preoperative and postoperative SVA values is outlined in Table 8 . The SVA value decreased to $<50 \mathrm{~mm}$ after surgery in 23 patients from Group B (52.3\%). On the other hand, 12 patients from Group A (18.5\%) had worse SVA values $\geq 50 \mathrm{~mm}$ after surgery. The demographic and clinical characteristics of these groups are summarized in Table 9. Patients in Group D were statistically significantly older than those in Group C $(73.3 \pm 9.2$ years vs $69.5 \pm 8.6$ years, $p=0.045$ ).

We further analyzed the effect of postoperative sagittal imbalance on clinical and HRQOL outcomes. Patients in Group D had significantly lower preoperative and postoperative JOABPEQ scores in terms of walking ability and social-life function than those in Group C (preoperative walking ability: $22.7 \pm 26.0$ vs $36.6 \pm 26.3, p=0.038$; postoperative walking ability: $42.5 \pm 29.6$ vs $71.1 \pm 30.4$, $\mathrm{p}<0.001$; preoperative social-life function: $30.2 \pm 16.7 \mathrm{vs}$ $38.7 \pm 18.5, \mathrm{p}=0.045$; postoperative social-life function: $49.6 \pm 20.0$ vs $67.0 \pm 25.8, p=0.001$; Table 10). Patients in
TABLE 5. Mean RMDQ and JOA scores in 109 patients treated for LCS, grouped according to preoperative SVA values*

\begin{tabular}{lccc}
\hline Measure & Group A & Group B & p Value \\
\hline RMDQ & & & \\
Preop & $10.7 \pm 5.7$ & $10.8 \pm 5.6$ & 0.928 \\
Postop & $5.6 \pm 5.5$ & $6.2 \pm 5.7$ & 0.591 \\
\hline JOA & & & \\
Preop & $15.9 \pm 4.6$ & $15.0 \pm 4.9$ & 0.323 \\
Postop & $24.5 \pm 3.5$ & $24.2 \pm 4.2$ & 0.771 \\
Recovery rate (\%) & $65.9 \pm 26.2$ & $65.3 \pm 27.3$ & 0.607 \\
\hline * Recovery rate was calculated as (postoperative JOA score - preoperative \\
JOA score)/(29 - preoperative JOA score) × 100 (\%).
\end{tabular}

Group D had significantly higher postoperative VAS LBP scores and RMDQ scores than those in Group C (VAS LBP: $3.94 \pm 2.59$ vs $2.68 \pm 2.69$, respectively, $\mathrm{p}=0.039$; RMDQ: $7.9 \pm 5.7$ vs $4.9 \pm 5.2$, $\mathrm{p}=0.015$; Tables 11 and 12 ). Moreover, postoperative JOA scores were significantly lower in Group D than in Group C $(23.0 \pm 4.1$ vs 25.2 $\pm 3.4, \mathrm{p}=0.012$ ). While the JOA score recovery rate did not differ significantly between the 2 groups, patients with postoperative sagittal imbalance (Group D) tended toward a lower recovery rate $(59.5 \% \pm 24.5 \%$ vs $69.6 \% \pm 27.8 \%$, $\mathrm{p}=0.065)$. These results suggested that residual sagittal malalignment is negatively associated with clinical outcome after lumbar decompression surgery in LCS patients and that a high postoperative SVA is correlated with LBP and HRQOL scores.

\section{Discussion}

Sagittal spinal alignment is an important factor in the management of lumbar degenerative diseases and LBP. Lumbar decompressive surgery without spinal fusion is the first choice of surgical treatment for degenerative LCS. Sagittal spinopelvic malalignment is a major cause of pain and loss of function associated with adult spinal deformity. ${ }^{1,9,15}$ Surgical restoration of optimal sagittal alignment is indicated for patients with symptomatic adult spinal deformity and offers superior clinical and radiographic outcomes over those obtained with nonoperative management. ${ }^{3,26}$ However, the impact of sagittal spinopelvic alignment on clinical outcomes after lumbar decompression surgery for LCS without coronal imbalance has not been clarified.

The importance of sagittal plane deformity is well documented, particularly with reference to postsurgical flatback syndrome and posttraumatic kyphosis. ${ }^{16}$ Studies have shown that realigning the SVA is critical for optimizing clinical outcomes. High SVA values are correlated with pain, loss of function, and poor HRQOL. ${ }^{15}$ The severity of clinical symptoms increases in a linear fashion with progressive sagittal imbalance. ${ }^{9}$ Jackson and Hales identified normative values for these radiographic spinopelvic parameters, indicating that the SVA should be $<50 \mathrm{~mm} .{ }^{10}$ Therefore, we grouped patients according to whether their SVA was $<50 \mathrm{~mm}$ or $\geq 50 \mathrm{~mm}$. As described in Results, pelvic retroversion and loss of lumbar lordosis were observed prior to surgery in LCS patients with preoperative 
TABLE 6. Changes in radiological parameters after decompression surgery in 109 patients treated for LCS, grouped according to preoperative SVA values

\begin{tabular}{|c|c|c|c|c|c|c|c|c|}
\hline \multirow[b]{2}{*}{ Parameter } & \multicolumn{4}{|c|}{ Group A } & \multicolumn{4}{|c|}{ Group B } \\
\hline & Preop & Postop & Change & $p$ Value & Preop & Postop & Change & $p$ Value \\
\hline SVA (mm) & $22.8 \pm 19.9$ & $24.8 \pm 38.2$ & $2.0 \pm 38.8$ & 0.703 & $76.3 \pm 29.7$ & $54.3 \pm 39.8$ & $-21.9 \pm 32.6$ & $0.004^{*}$ \\
\hline LL: T12-S1 ( $\left.{ }^{\circ}\right)$ & $-39.8 \pm 13.0$ & $-41.0 \pm 13.5$ & $-1.2 \pm 8.7$ & 0.618 & $-26.8 \pm 15.5$ & $-33.6 \pm 14.2$ & $-6.8 \pm 8.0$ & $0.035^{*}$ \\
\hline $\operatorname{Cobb}\left({ }^{\circ}\right)$ & $6.4 \pm 5.9$ & $6.6 \pm 8.2$ & $0.1 \pm 5.3$ & 0.922 & $6.7 \pm 5.4$ & $7.3 \pm 6.5$ & $0.5 \pm 4.3$ & 0.678 \\
\hline $\mathrm{PT}\left({ }^{\circ}\right)$ & $19.7 \pm 8.1$ & $17.1 \pm 9.0$ & $-2.6 \pm 6.5$ & 0.081 & $24.2 \pm 9.8$ & $20.1 \pm 9.6$ & $-4.1 \pm 6.9$ & 0.053 \\
\hline $\operatorname{SS}\left({ }^{\circ}\right)$ & $27.4 \pm 8.7$ & $30.0 \pm 8.3$ & $2.6 \pm 6.5$ & 0.080 & $24.2 \pm 9.5$ & $28.3 \pm 8.8$ & $4.1 \pm 6.9$ & $0.041^{*}$ \\
\hline TK: T5-12 $\left(^{\circ}\right)$ & $22.1 \pm 10.3$ & $23.5 \pm 12.0$ & $1.5 \pm 5.3$ & 0.455 & $17.9 \pm 10.8$ & $21.1 \pm 9.7$ & $3.3 \pm 6.2$ & 0.136 \\
\hline TLK: T10-L2 $\left(^{\circ}\right)$ & $5.7 \pm 7.5$ & $5.6 \pm 8.8$ & $-0.1 \pm 5.3$ & 0.949 & $7.9 \pm 10.0$ & $8.0 \pm 12.2$ & $0.1 \pm 6.1$ & 0.981 \\
\hline
\end{tabular}

* Statistically significant.

sagittal imbalance. Patients with LCS bend forward to gain relief from LBP or related symptoms and thus increase the available space in the lumbar spinal canal. Long periods of forward-bending posture in daily life may lead to reduced strength and degenerative atrophy of the paraspinal muscle. In the present study, preoperative sagittal imbalance was improved after decompression surgery, suggesting that the preoperative posture was reversible and that the lumbar extensor muscles might not have fallen into an irreversible degenerative change before surgery. We noted that the SVA value for Group B, which had more than 50 $\mathrm{mm}$ of SVA preoperatively, significantly improved after
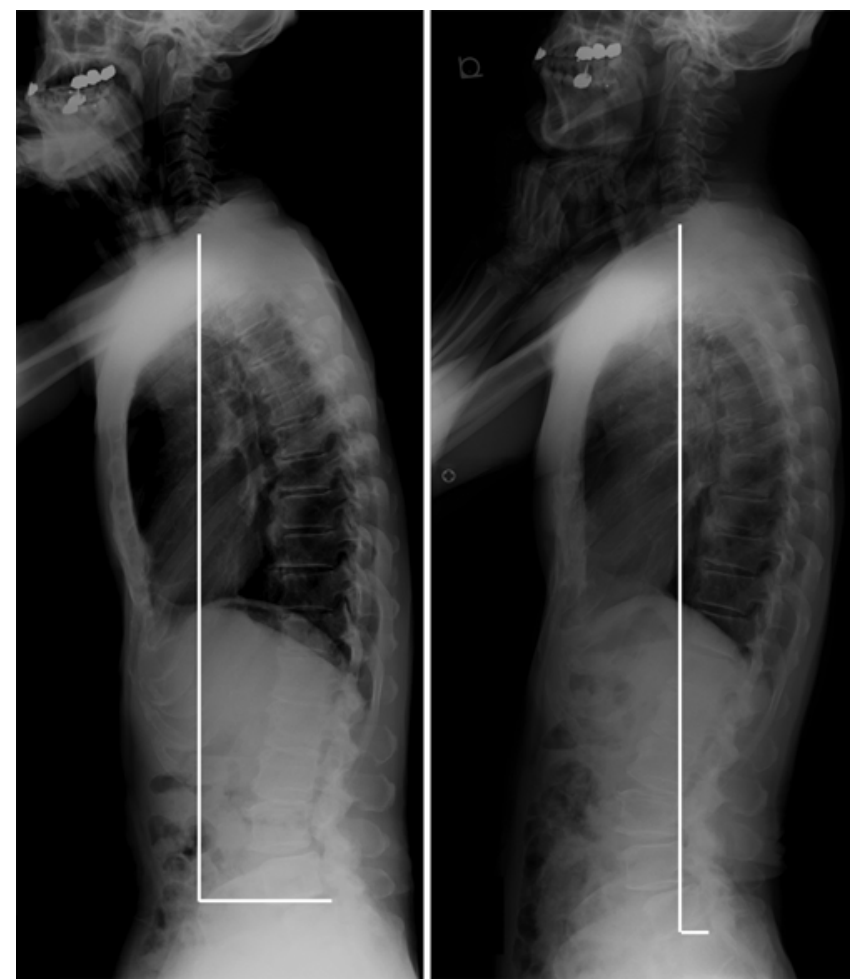

FIG. 1. Improvement in SVA after decompression surgery. Preoperative (left) and postoperative (right) lateral radiographs of the whole spine. The patient was a 70-year-old male with right leg pain and neurological claudication. The SVA improved after lumbar decompression surgery at L3-4 and L4-5. decompression surgery, whereas the patients with severe preoperative sagittal imbalance (SVA $>80 \mathrm{~mm}$ ) in Group $\mathrm{B}$ had residual postoperative sagittal imbalance $(>50 \mathrm{~mm}$; Tables 6 and 7). These results indicated that the sagittal realignment effect of lumbar decompression surgery was limited for the LCS patients with severe preoperative sagittal imbalance. Therefore, we suggest that a preoperative SVA $>80 \mathrm{~mm}$ may be one of the predictors of residual sagittal imbalance after lumbar decompression surgery. Twelve (18.5\%) of 65 patients in Group A had a postoperative deterioration in SVA to more than $50 \mathrm{~mm}$. Although we tried to analyze the risk factor for postoperative deterioration in SVA (from Group A to Group D), we could not clarify the risk factor for after decompression surgery. Therefore, we need further studies with larger sample sizes, which may bring novel and interesting findings.

Several studies have reported relationships between LBP and radiological abnormalities in the lumbar spine. In a cross-sectional study, Kellgren and Lawrence found an association between radiological changes and past LBP. ${ }^{13}$ On the other hand, Frymoyer et al. reported that single disc-space narrowing and vertebral osteophytes were equally prevalent in symptomatic and asymptomatic men. ${ }^{7}$ Lundin et al. found no correlation between LBP and any specific radiological abnormalities. ${ }^{18}$ Thus, relationships between LBP and radiological abnormalities in the lumbar spine have been a matter of debate. However, authors of recent large-scale epidemiological studies have reported that lumbar degenerative changes are the main risk factors for LBP, 4,17 although these studies focused only on local degenerative changes. We investigated global radiological findings of the spine and demonstrated that preoperative sagittal imbalance in LCS patients without coronal imbal-

TABLE 7. Changes in SVA values after decompression surgery in patients with preoperative SVA values $\geq 50 \mathrm{~mm}$

\begin{tabular}{ccccc}
\hline Group & Preop & Postop & Change & p Value \\
\hline B1 $^{*}(n=31)$ & $60.4 \pm 8.4$ & $42.4 \pm 32.8$ & $-18.1 \pm 35.9$ & $0.005 \ddagger$ \\
\hline B2† $(n=13)$ & $114.0 \pm 28.2$ & $82.8 \pm 41.6$ & $-31.2 \pm 36.6$ & $0.036 \ddagger$ \\
\hline
\end{tabular}

* SVA $50-80 \mathrm{~mm}$.

$\dagger \mathrm{SVA}>80 \mathrm{~mm}$.

$\ddagger$ Statistically significant. 
TABLE 8. Distribution of patients according to preoperative and postoperative SVA

\begin{tabular}{|c|c|c|c|}
\hline \multirow[b]{2}{*}{ Postop Groups } & \multicolumn{2}{|c|}{ Preop Groups } & \multirow[b]{2}{*}{ Total } \\
\hline & $A$ & B & \\
\hline C & 53 & 23 & 76 \\
\hline$D$ & 12 & 21 & 33 \\
\hline Total & 65 & 44 & 109 \\
\hline
\end{tabular}

ance did not affect the preoperative LBP. In contrast, the residual sagittal imbalance after decompression surgery was significantly correlated with postoperative LBP.

Patient-reported outcome questionnaires have become the standard measure of therapeutic effectiveness following spine surgery. The problem with these questionnaires is that their numerical scores lack a direct, clinically significant meaning. ${ }^{14}$ Because of this, the concept of a minimum clinically important difference (MCID) has recently been put forth as a measure of the clinical threshold needed to achieve treatment effectiveness. Roland and Fairbank suggested 2 points as the MCID for the RMDQ. ${ }^{22}$ In the present study, 52 (68.4\%) of 76 patients in Group C and 19 $(57.6 \%)$ of 33 patients in Group D met this threshold. Parker et al. and Copay et al. reported 2 points as the MCID for VAS LBP. In our study, 41 (53.9\%) of 76 patients in Group $\mathrm{C}$ and $15(45.4 \%)$ of 33 patients in Group D met this threshold. ${ }^{619-21}$ The number of patients who met the MCID for

TABLE 9. Demographic and clinical characteristics of 109 patients treated for LCS, grouped according to postoperative SVA values

\begin{tabular}{|c|c|c|c|}
\hline Parameter & Group C & Group D & $\mathrm{p}$ Value \\
\hline No. & 76 & 33 & \\
\hline Mean age in yrs & $69.5 \pm 8.6$ & $73.3 \pm 9.2$ & 0.045 \\
\hline $\operatorname{Sex}(M / F)$ & $45 / 31$ & $20 / 13$ & 0.891 \\
\hline Mean FU period in yrs & $2.6 \pm 0.8$ & $2.5 \pm 0.9$ & 0.897 \\
\hline Mean disease duration in yrs & $3.7 \pm 3.3$ & $3.9 \pm 3.6$ & 0.835 \\
\hline $\begin{array}{l}\text { Decompression segments } \\
\text { (no. of cases) }\end{array}$ & & & 0.225 \\
\hline 1 & 32 & 15 & \\
\hline 2 & 32 & 9 & \\
\hline 3 & 12 & 9 & \\
\hline $\begin{array}{l}\text { Mean no. decompression } \\
\text { segments }\end{array}$ & $1.8 \pm 0.8$ & $1.8 \pm 0.8$ & 0.691 \\
\hline $\begin{array}{l}\text { Decompression level (no. of } \\
\text { cases) }\end{array}$ & & & 0.368 \\
\hline L1-2 & 2 & 1 & \\
\hline L2-3 & 15 & 12 & \\
\hline L3-4 & 45 & 19 & \\
\hline L4-5 & 68 & 28 & \\
\hline L5-S1 & 4 & 0 & \\
\hline Mean EBL in $\mathrm{g}$ & $28.6 \pm 69.7$ & $22.6 \pm 54.1$ & 0.629 \\
\hline Mean operation time in min & $65.6 \pm 30.6$ & $67.8 \pm 28.8$ & 0.721 \\
\hline
\end{tabular}

TABLE 10. Mean JOABPEQ scores in 109 patients treated for LCS, grouped according to postoperative SVA

\begin{tabular}{lccc}
\hline Parameter & Group C & Group D & p Value \\
\hline LBP & & & \\
Preop & $40.6 \pm 32.5$ & $39.6 \pm 26.8$ & 0.891 \\
Postop & $73.1 \pm 35.5$ & $59.1 \pm 33.1$ & 0.112 \\
\hline Lumbar function & & & \\
$\quad$ Preop & $55.7 \pm 24.1$ & $49.6 \pm 29.9$ & 0.397 \\
$\quad$ Postop & $73.7 \pm 30.0$ & $68.1 \pm 24.1$ & 0.398 \\
\hline Walking ability & & & \\
Preop & $36.6 \pm 26.3$ & $22.7 \pm 26.0$ & $0.038^{*}$ \\
$\quad$ Postop & $71.1 \pm 30.4$ & $42.5 \pm 29.6$ & $<0.001^{*}$ \\
\hline Social-life function & & & \\
$\quad$ Preop & $38.7 \pm 18.5$ & $30.2 \pm 16.7$ & $0.045^{*}$ \\
$\quad$ Postop & $67.0 \pm 25.8$ & $49.6 \pm 20.0$ & $0.001^{*}$ \\
\hline Mental health & & & \\
Preop & $44.0 \pm 17.4$ & $40.4 \pm 20.6$ & 0.462 \\
Postop & $59.4 \pm 18.7$ & $51.9 \pm 14.7$ & 0.055 \\
\hline
\end{tabular}

* Statistically significant.

these instruments was greater in Group $C$ than in Group $\mathrm{D}$; however, there were no significant differences between the 2 groups. We could not assess how many patients met the MCID for the JOABPEQ in the 2 groups because no studies have assessed the MCID for the JOABPEQ in the lumbar degenerative diseases.

In our study, we assessed clinical outcome and radiological parameters in the preoperative and final followup periods. The final follow-up was performed at least 1 year postoperatively (range 1.0-4.2 years), and the mean follow-up period was 2.6 years. Therefore, we need further studies with longer follow-ups to clarify the impact of decompression surgery on changes in sagittal spinopelvic alignment, clinical outcome, and HRQOL scores. Data in the present study indicated that clinical and HRQOL outcomes after decompression surgery for LCS were not associated with preoperative sagittal alignment; however,

TABLE 11. Mean VAS scores in 109 patients treated for LCS, grouped according to postoperative SVA*

\begin{tabular}{cccl}
\hline Parameter & Group C & Group D & p Value \\
\hline LBP & & & \\
Preop & $5.42 \pm 2.89$ & $5.98 \pm 2.45$ & 0.349 \\
Postop & $2.68 \pm 2.69$ & $3.94 \pm 2.59$ & $0.039 \dagger$ \\
Change & $2.75 \pm 3.55$ & $2.04 \pm 2.45$ & 0.273 \\
\hline Leg pain & & & \\
Preop & $6.70 \pm 2.73$ & $7.13 \pm 1.94$ & 0.392 \\
Postop & $2.93 \pm 3.12$ & $3.53 \pm 3.03$ & 0.348 \\
Change & $3.77 \pm 3.58$ & $3.60 \pm 3.39$ & 0.826 \\
Leg numbness & & & \\
Preop & $6.86 \pm 2.41$ & $6.26 \pm 2.73$ & 0.313 \\
Postop & $3.76 \pm 3.38$ & $4.07 \pm 3.06$ & 0.662 \\
Change & $3.10 \pm 3.88$ & $2.19 \pm 3.37$ & 0.254 \\
\hline
\end{tabular}

* Change is calculated as (postoperative value - preoperative value).

$\dagger$ Statistically significant. 
TABLE 12. Mean RMDQ and JOA scores in 109 patients treated for LCS, grouped according to postoperative SVA

\begin{tabular}{lrrl}
\hline \multicolumn{1}{c}{ Measure } & Group C & Group D & p Value \\
\hline RMDQ & & & \\
Preop & $10.0 \pm 5.8$ & $12.1 \pm 5.1$ & 0.069 \\
Postop & $4.9 \pm 5.2$ & $7.9 \pm 5.7$ & $0.015^{*}$ \\
\hline JOA & & \\
Preop & $16.1 \pm 4.5$ & $14.2 \pm 4.9$ & 0.07 \\
Postop & $25.2 \pm 3.4$ & $23.0 \pm 4.1$ & $0.012^{*}$ \\
Recovery rate (\%) $\dagger$ & $69.6 \pm 27.8$ & $59.5 \pm 24.5$ & 0.065 \\
\hline * Statistically significant. & & \\
$\dagger$ & Recovery rate is calculated as (postoperative JOA score - preoperative JOA \\
score)/(29 - preoperative JOA score) $\times 100(\%)$.
\end{tabular}

patients with an SVA $<50 \mathrm{~mm}$ at the final follow-up had significantly less LBP and disability than those with a postoperative SVA $\geq 50 \mathrm{~mm}$. Postoperative residual sagittal imbalance (postoperative SVA $\geq 50 \mathrm{~mm}$ ) in LCS patients without coronal imbalance was strongly correlated with LBP at the final follow-up as well as with losses in walking ability and in the social function score at the final follow-up. Our results are consistent with previous reports that postoperative radiological parameters, including SVA, are strongly correlated with HRQOL scores in patients with adult spinal deformity. ${ }^{15,24}$ Although the SVA value in patients with severe preoperative sagittal imbalance $(>80$ $\mathrm{mm}$ ) improved after decompression surgery, there was residual sagittal imbalance at the final follow-up. Therefore, we speculate that LCS patients with severe preoperative imbalance require decompression surgery with corrective fusion to restore their global spinal sagittal alignment.

This study has several limitations. First, it was a small retrospective case series with a short-term follow-up. A prospective study with a larger sample size and longer follow-up should be conducted to confirm our findings. Second, patients with severe LBP due to sagittal imbalance, who would require correction and fusion surgery, were excluded from this study, and we were unable to clarify precise cutoffs for an acceptable preoperative SVA and residual postoperative SVA in the LCS patients.

\section{Conclusions}

This study demonstrated that preoperative sagittal balance was not significantly correlated with clinical or HRQOL outcomes after decompression surgery in LCS patients without coronal imbalance. Decompression surgery improved the SVA value in patients with preoperative sagittal imbalance; however, the patients with severe preoperative sagittal imbalance had residual imbalance after decompression surgery. Postoperative residual sagittal imbalance had a negative impact on clinical and HRQOL outcomes after surgery in LCS patients without coronal imbalance.

\section{References}

1. Baldus C, Bridwell KH, Harrast J, Edwards C II, Glassman S, Horton W, et al: Age-gender matched comparison of SRS in- strument scores between adult deformity and normal adults: are all SRS domains disease specific? Spine (Phila Pa 1976) 33:2214-2218, 2008

2. Barrey C, Jund J, Noseda O, Roussouly P: Sagittal balance of the pelvis-spine complex and lumbar degenerative diseases. A comparative study about 85 cases. Eur Spine J 16:14591467, 2007

3. Bridwell KH, Glassman S, Horton W, Shaffrey C, Schwab F, Zebala LP, et al: Does treatment (nonoperative and operative) improve the two-year quality of life in patients with adult symptomatic lumbar scoliosis: a prospective multicenter evidence-based medicine study. Spine (Phila Pa 1976) 34:2171-2178, 2009

4. Cheung KM, Karppinen J, Chan D, Ho DW, Song YQ, Sham $P$, et al: Prevalence and pattern of lumbar magnetic resonance imaging changes in a population study of one thousand fortythree individuals. Spine (Phila Pa 1976) 34:934-940, 2009

5. Chiba K, Toyama Y, Matsumoto M, Maruiwa H, Watanabe M, Nishizawa T: Intraspinal cyst communicating with the intervertebral disc in the lumbar spine: discal cyst. Spine (Phila Pa 1976) 26:2112-2118, 2001

6. Copay AG, Glassman SD, Subach BR, Berven S, Schuler TC, Carreon LY: Minimum clinically important difference in lumbar spine surgery patients: a choice of methods using the Oswestry Disability Index, Medical Outcomes Study questionnaire Short Form 36, and pain scales. Spine J 8:968-974, 2008

7. Frymoyer JW, Newberg A, Pope MH, Wilder DG, Clements $\mathrm{J}$, MacPherson B: Spine radiographs in patients with lowback pain. An epidemiological study in men. J Bone Joint Surg Am 66:1048-1055, 1984

8. Fukui M, Chiba K, Kawakami M, Kikuchi S, Konno S, Miyamoto M, et al: JOA Back Pain Evaluation Questionnaire (JOABPEQ)/JOA Cervical Myelopathy Evaluation Questionnaire (JOACMEQ). The report on the development of revised versions. April 16, 2007. J Orthop Sci 14:348-365, 2009

9. Glassman SD, Bridwell K, Dimar JR, Horton W, Berven S, Schwab F: The impact of positive sagittal balance in adult spinal deformity. Spine (Phila Pa 1976) 30:2024-2029, 2005

10. Jackson RP, Hales C: Congruent spinopelvic alignment on standing lateral radiographs of adult volunteers. Spine (Phila Pa 1976) 25:2808-2815, 2000

11. Jackson RP, McManus AC: Radiographic analysis of sagittal plane alignment and balance in standing volunteers and patients with low back pain matched for age, sex, and size. A prospective controlled clinical study. Spine (Phila Pa 1976) 19:1611-1618, 1994

12. Jang JS, Lee SH, Kim JM, Min JH, Han KM, Maeng DH: Can patients with sagittally well-compensated lumbar degenerative kyphosis benefit from surgical treatment for intractable back pain? Neurosurgery 64:115-121, 2009

13. Kellgren JH, Lawrence JS: Osteo-arthrosis and disk degeneration in an urban population. Ann Rheum Dis 17:388-397, 1958

14. Kulkarni AV: Distribution-based and anchor-based approaches provided different interpretability estimates for the Hydrocephalus Outcome Questionnaire. J Clin Epidemiol 59:176-184, 2006

15. Lafage V, Schwab F, Patel A, Hawkinson N, Farcy JP: Pelvic tilt and truncal inclination: two key radiographic parameters in the setting of adults with spinal deformity. Spine (Phila Pa 1976) 34:E599-E606, 2009

16. Lagrone MO, Bradford DS, Moe JH, Lonstein JE, Winter RB, Ogilvie JW: Treatment of symptomatic flatback after spinal fusion. J Bone Joint Surg Am 70:569-580, 1988

17. Livshits G, Popham M, Malkin I, Sambrook PN, Macgregor AJ, Spector T, et al: Lumbar disc degeneration and genetic factors are the main risk factors for low back pain in women: 
the UK Twin Spine Study. Ann Rheum Dis 70:1740-1745, 2011

18. Lundin O, Hellström M, Nilsson I, Swärd L: Back pain and radiological changes in the thoraco-lumbar spine of athletes. A long-term follow-up. Scand J Med Sci Sports 11:103-109, 2001

19. Parker SL, Adogwa O, Paul AR, Anderson WN, Aaronson $\mathrm{O}$, Cheng JS, et al: Utility of minimum clinically important difference in assessing pain, disability, and health state after transforaminal lumbar interbody fusion for degenerative lumbar spondylolisthesis. J Neurosurg Spine 14:598-604, 2011

20. Parker SL, Mendenhall SK, Shau D, Adogwa O, Cheng JS, Anderson WN, et al: Determination of minimum clinically important difference in pain, disability, and quality of life after extension of fusion for adjacent-segment disease. J Neurosurg Spine 16:61-67, 2012

21. Parker SL, Mendenhall SK, Shau DN, Adogwa O, Anderson WN, Devin CJ, et al: Minimum clinically important difference in pain, disability, and quality of life after neural decompression and fusion for same-level recurrent lumbar stenosis: understanding clinical versus statistical significance. J Neurosurg Spine 16:471-478, 2012

22. Roland M, Fairbank J: The Roland-Morris Disability Questionnaire and the Oswestry Disability Questionnaire. Spine (Phila Pa 1976) 25:3115-3124, 2000

23. Rose PS, Bridwell KH, Lenke LG, Cronen GA, Mulconrey DS, Buchowski JM, et al: Role of pelvic incidence, thoracic kyphosis, and patient factors on sagittal plane correction following pedicle subtraction osteotomy. Spine (Phila Pa 1976) 34:785-791, 2009

24. Schwab FJ, Blondel B, Bess S, Hostin R, Shaffrey CI, Smith JS, et al: Radiographical spinopelvic parameters and disability in the setting of adult spinal deformity: a prospective multicenter analysis. Spine (Phila Pa 1976) 38:E803-E812, 2013

25. Smith A, O'Sullivan P, Straker L: Classification of sagittal thoraco-lumbo-pelvic alignment of the adolescent spine in standing and its relationship to low back pain. Spine (Phila Pa 1976) 33:2101-2107, 2008

26. Smith JS, Shaffrey CI, Berven S, Glassman S, Hamill C, Horton W, et al: Operative versus nonoperative treatment of leg pain in adults with scoliosis: a retrospective review of a prospective multicenter database with two-year follow-up. Spine (Phila Pa 1976) 34:1693-1698, 2009

27. Watanabe K, Hosoya T, Shiraishi T, Matsumoto M, Chiba K, Toyama Y: Lumbar spinous process-splitting laminectomy for lumbar canal stenosis. Technical note. J Neurosurg Spine 3:405-408, 2005

\section{Author Contributions}

Conception and design: Hikata. Acquisition of data: Hikata. Analysis and interpretation of data: Hikata. Drafting the article: Hikata. Critically revising the article: Hikata. Reviewed submitted version of manuscript: Matsumoto, Hikata. Approved the final version of the manuscript on behalf of all authors: Matsumoto. Statistical analysis: Hikata. Administrative/technical/material support: Hikata. Study supervision: Matsumoto, Watanabe, Fujita, Iwanami, Hosogane, Ishii, Nakamura, Toyama.

\section{Correspondence}

Morio Matsumoto, Department of Orthopaedic Surgery, Keio University School of Medicine, 35 Shinanomachi, Shinjyuku, Tokyo, Japan. email: morio@a5.keio.jp. 